\title{
Laparoscopy versus laparotomy for surgical treatment of obese women with endometrial cancer: A cost-benefit comparative analysis
}

\author{
VITO ANDREA CAPOZZI ${ }^{1}$, GIULIO SOZZI ${ }^{2}$, GIULIA GAMBINO ${ }^{1}$, ALESSANDRA CIANCIOLO ${ }^{1}$, \\ MATTEO RICCO $^{3}{ }^{3}$, LUCIANO MONFARDINI ${ }^{1}$, MICHELA GAIANO ${ }^{1}$, VITO CHIANTERA ${ }^{2}$, \\ STEFANO UCCELLA ${ }^{4}$ and ROBERTO BERRETTA ${ }^{1}$
}

\footnotetext{
${ }^{1}$ Department of Gynecology and Obstetrics, University of Parma, I-43125 Parma; ${ }^{2}$ Department of Gynecologic Oncology, University of Palermo, I-90127 Palermo; ${ }^{3}$ Department of Public Health, Workplace Prevention and Safety Service,

AUSL1-I.R.C.C.S. di Reggio Emilia, Service for Health and Safety on The Workplaces, I-42122 Reggio;

${ }^{4}$ Obstetrics and Gynecology Department, Ospedale degli Infermi, I-13875 Biella, Italy
}

Received April 17,2019; Accepted June 21, 2019

DOI: $10.3892 / \mathrm{mco} .2019 .1901$

\begin{abstract}
The aim of the present study was to demonstrate the cost of obese patients affected by endometrial cancer undergoing open surgery compared with minimally invasive surgery. In the retrospective cohort study (Canadian Task Force classification II-2), the economic expenditure in pre-operative, intra-operative and post-operative phases of the selected patients was evaluated. Costs were analyzed for all blood tests, instrumental examinations, consultations, operating materials, drugs, gynecological examinations, hospital stay, intensive care hospitalization and management of operative complications. The average length of stay was longer for patients who underwent laparotomy, with an almost double median hospitalization cost in the open abdominal group compared with the laparoscopic group ( $€ 4,805.37$ vs. $€ 2,589.25$; $\mathrm{P}<0.0001)$. Evaluation by another specialist (cardiologist, diabetologist, internist) was necessary in $30.9 \%$ of laparotomies vs. $10.4 \%$ of laparoscopies $(\mathrm{P}=0.003)$. A respiratory support was applied to 38 patients $(28.8 \%)$, of whom $23(41.8 \%)$ were in the open abdominal arm $(\mathrm{P}=0.011)$. Antibiotic and pain-relief therapies resulted in a significantly higher cost for the open abdominal than for the minimally-invasive approach $(\mathrm{P}=0.027)$. Considering all the pre-, intra- and post-operative course, the expenses for an obese patient operated by laparoscopy was $€ 4,412.41$ vs. $€ 7,323.17$ by open surgery, with an average saving of $€ 2,911.03$ in favor of minimally-invasive surgery.
\end{abstract}

Correspondence to: Dr Roberto Berretta or Dr Vito Andrea Capozzi, Department of Gynecology and Obstetrics, University of Parma, via Gramsci 14, I-43125 Parma, Italy

E-mail: roberto.berrettamd@gmail.com

E-mail: vitoandrea.capozzi@studenti.unipr.it

Key words: obese, endometrial cancer, laparoscopy, open surgery, costs, economic expenditure
This study revealed that in obese patients with endometrial cancer, minimally invasive surgery is more advantageous both in terms of costs and post-operative complications. To conclude, laparoscopic surgery in obese patients allows an economic saving of $\sim 60 \%$ less than open surgery.

\section{Introduction}

Obesity represents a major health problem: Its incidence is growing all over the world and it is associated with an increased risk of cardiovascular disease, type II diabetes mellitus, hypertension, heart attack, dyslipidemia, osteoarthritis and several cancers (1).

Worldwide, the number of obese people has doubled since 1980: In 2014, over 1.9 billion adults were overweight, including over 600 million obese (1). Data referring to the year 2013 show that in Europe over $50 \%$ of the adult population was overweight and over $20 \%$ was obese (2). The Italian Public Report on National Health shows that in 2015, more than a third of the adult population $(35.3 \%$ ) was overweight, and $9.8 \%$ of persons were obese; of note, the percentage of excess-weight population increases with age, and in the Italian context, overweight and obesity increase from 14 and $2.3 \%$ at 18-24 years of age to 46 and $15.3 \%$ in the category of patients between $65-74$ years, respectively (3). In a cross-sectional analysis, Arterburn et al reported that morbid obesity $\left(\mathrm{BMI} \geq 40 \mathrm{~kg} / \mathrm{m}^{2}\right)$ is associated with an $81 \%$ greater health care expenditure per capita compared with normal weight adults in the US, with an excess of more than 11 billion dollars spent per year (4). Moreover, obesity is actually associated with huge indirect costs, due to the co-existence of several co-morbidities (diabetes, hypertension, cardiovascular problems), need for intense preoperative assessments, perioperative complications, conversion from laparoscopic to open surgery, intensive postoperative care (IPC), higher treatment costs and reduced recurrence-free survival $(5,6)$. Obesity is now considered a global epidemic; in a society that is increasingly trying to reduce health-care expenses, it is essential to analyze the costs associated with the management of these patients. 
Endometrial cancer is the most common gynecological malignancy in Western countries and most of these tumors are associated with obesity $(7,8)$. As a consequence, the increasing prevalence of obesity translates into a growth in the incidence of endometrial cancer. Since the early '90 sec, several authors have reported their experience with laparoscopic treatment of clinical stage I endometrial cancer (9-11). After the publication of the results of the LAP-2 trial, laparoscopy has become the elective treatment for this malignancy, due to the more favorable complication rates, the shorter hospital stay and the similar oncological outcomes, compared to open surgery (12).

From a surgical point of view the obese woman turns out to be a complex patient; in fact, the laparoscopic learning curve is harsher than for normal-weight subjects, especially when lymphadenectomy is to be performed $(13,14)$. Some studies report that in $10 \%$ of cases the obese patient is inoperable for the presence of medical comorbidities and in $20 \%$ of cases the affected woman is under-staged due to surgical complexity (15-17).

Robotic surgery has been proposed to overcome some of the difficulties in operating obese patients, maintaining the same benefits of laparoscopic surgery and providing a better exposure of the operative field, although it may be disadvantageous with respect to economic considerations (18).

Although several studies have investigated costs of laparoscopic vs. open approach for endometrial cancer, very few data are available in selected population of patients, such as obese women (19-22).

The aim of this study has been to evaluate pre-, intra- and post-operative costs in obese women affected by endometrial cancer comparing laparoscopic vs. open abdominal surgery. As a secondary outcome, we evaluated the feasibility of laparoscopic surgery in obese women analyzing intraoperative, early and late postoperative complications, in comparison with open surgery.

\section{Patients and methods}

The present study represents a retrospective analysis of the oncological database of the Gynecology and Obstetrics Department of the University Hospital of Parma from January 2007 to December 2017. Five-hundred-forty patients underwent surgery for endometrial cancer in the study period. Of them, $132(24.4 \%)$ were obese (BMI $\geq 30)$. These subjects were included in the study and they were divided into two groups (laparoscopic and open abdominal), according to the initial surgical approach. Patients were stratified into the four different classes of obesity [class I $(<35)$, class II $(<40)$, class III $(<45)$, class IV $(>45)(23,24)]$. Patients characteristics are shown in Table I.

Before December 2015, lymphadenectomy was performed in case of grade 2-3 disease and/or myometrial invasion $>50 \%$. After December 2015, lymph node dissection was accomplished in selected cases according to the ESGO-ESMO-ESTRO consensus conference recommendations (25).

The patients were operated by laparoscopy or open surgery according to the preference and experience of the surgeons involved. Two expert oncologist surgeon gynecologists were included during the study period.

Preoperative phase. Medical history and clinical characteristics were collected in all patients pre-operatively. Preoperative work-up included blood tests, electrocardiogram, blood gas analysis and Total Body CT scan. In case of comorbidities, further examinations and consultations were requested such as spirometry, echocardiogram, lower limb eco-Doppler, chest X-ray, urine test, cardiology, endocrinology or internal medicine counseling.

Operative technique. Access into the abdominal cavity was obtained using a $10-\mathrm{mm}$ optical trocar inserted transumbilically. Pneumoperitoneum was maintained at $12 \mathrm{~mm} \mathrm{Hg}$. Three $5 \mathrm{~mm}$ ancillary trocars were inserted in the suprapubic area. All patients underwent class. A Hysterectomy according to Q-M classification (26) and bilateral salpingo-oophorectomy. Pelvic and aortic lymphadenectomy were performed, depending on the case as previously specified. In selected cases, suspension of the sigmoid and cecum was accomplished to obtain a better exposure of the operative field. A Rumi uterine manipulator was used (27). The maximum Trendelemburg tolerated by the patient was applied.

Laparotomy was performed with a vertical midline incision. The surgical steps resembled those of laparoscopic surgery.

Postoperative phase. The days of hospitalization, intensive care admission, number of blood tests and blood counts, use of thromboembolism therapy (elastic stockings and/or low molecular weight heparin), early postoperative complications (within 30 days from surgery) and late (over 30 days from surgery), request for specialist advice, possible oxygen therapy, instrumental examinations, possible antibiotic therapy, pain reliever type, were analyzed for both groups.Complications were classified according to the glossary of Chassagne and colleagues (28).

Analysis of costs. In order to make a comprehensive and precise cost analysis, we considered the single cost of each day spent in the different units (gynecology department and intensive care unit) and they were added to the cost of the surgery (laparoscopy vs. laparotomy) and all the single drug administrations (ie. type of medication received, number of actual administrations), other specialists' consultations, blood samples, imaging exams.

Regarding operative devices such as multifunction instruments, the total cost of all the single pieces used was calculated and then the average per capita expenditure was obtained.

All costs are expressed in euros $(€)$. They are updated to December 2017 and refer to the University Hospital of Parma in Emilia Romagna, Italy.

The costs of each benefit were provided by the General Directorate of the Hospital-University of Parma and the costs were adjusted for inflation. No reimbursement was asked to the patients, and the total cost was borne by the hospital-University of Parma.

In order to obtain a more complete and closer to reality estimate of the cost of an obese patient, the pre-operative costs were also included, although clearly these do not depend on the surgical approach but on the patient's comorbidities.

Statistical analysis. Continuous variables have been described as mean \pm standard deviation (DS). The same variables were initially analyzed with D'Agostino-Pearson tests to explore the distribution compared to a normal population. In the case of a test result with a 
Table I. Patient demographics (N=132).

\begin{tabular}{|c|c|c|c|c|}
\hline & All patients & Laparoscopy & Laparotomy & \\
\hline Characteristics & $n=132$ & $n=77(58.3 \%)$ & $n=55(41.7 \%)$ & P-value \\
\hline Age (years) & 65.4 & 66.0 & 64.6 & 0.430 \\
\hline Menopause & $118(89.4 \%)$ & $72(93.5 \%)$ & $46(83.6 \%)$ & 0.069 \\
\hline Age of menopause (years) & 51.4 & 51.1 & 51.8 & 0.389 \\
\hline Body mass index $\left(\mathrm{kg} / \mathrm{m}^{2}\right)$ & 35.9 & 35.8 & 36.2 & 0.683 \\
\hline$<35$ & $70(53.0 \%)$ & $41(53.2 \%)$ & $29(52.7 \%)$ & 0.951 \\
\hline $35-40$ & $34(25.8 \%)$ & $19(24.7 \%)$ & $15(27.3 \%)$ & \\
\hline $41-45$ & $19(14.4 \%)$ & $11(14.3 \%)$ & $8(14.5 \%)$ & \\
\hline$>45$ & $9(6.8 \%)$ & $6(7.8 \%)$ & $3(5.5 \%)$ & \\
\hline Comorbidity & $112(84.8 \%)$ & $66(85.7 \%)$ & $46(83.6 \%)$ & 0.743 \\
\hline Hypertension & $93(70.5 \%)$ & $58(75.3 \%)$ & $35(63.6 \%)$ & 0.147 \\
\hline Diabetes & $44(33.3 \%)$ & $21(27.3 \%)$ & $23(41.8 \%)$ & 0.081 \\
\hline Cardiovascular diseases & $30(22.7 \%)$ & $13(16.9 \%)$ & $17(30.9 \%)$ & 0.058 \\
\hline Hypothyroidism & $27(20.5 \%)$ & $22(28.9 \%)$ & $5(9.1 \%)$ & 0.006 \\
\hline Metabolic syndrome & $27(20.5 \%)$ & $17(22.1 \%)$ & $10(18.2 \%)$ & 0.584 \\
\hline Chronic pulmonary disease & $2(1.5 \%)$ & $1(1.3 \%)$ & $1(1.8 \%)$ & 0.810 \\
\hline Hemiplegia or paraplegia & $2(1.5 \%)$ & $1(1.3 \%)$ & $1(1.8 \%)$ & 0.810 \\
\hline Hyperthyroidism & $2(1.5 \%)$ & $0,-$ & $2(3.6 \%)$ & 0.092 \\
\hline $\mathrm{HBV} / \mathrm{HCV} / \mathrm{HIV}$ & $2(1.5 \%)$ & $1(1.3 \%)$ & $1(1.8 \%)$ & 0.810 \\
\hline Mutation of Leiden $\mathrm{V}$ factor & $1(0.8 \%)$ & $1(1.3 \%)$ & $0,-$ & 0.396 \\
\hline Nephrolithiasis & $1(0.8 \%)$ & $1(1.3 \%)$ & $0,-$ & 0.396 \\
\hline Neurological disease & $1(0.8 \%)$ & $1(1.3 \%)$ & $0,-$ & 0.396 \\
\hline \multicolumn{5}{|l|}{ ASA score } \\
\hline 2 & $55(41.7 \%)$ & $33(50.0 \%)$ & $22(40.7 \%)$ & 0.311 \\
\hline 3 & $65(49.2 \%)$ & $33(50.0 \%)$ & $32(59.3 \%)$ & \\
\hline
\end{tabular}

value of $\mathrm{P}>0.100$, the variables were considered normally distributed, and the comparison between them was performed with the Student's t test or or one-way Analysis of Variance (ANOVA) with Tukey's post-hoc test, where appropriate. In the case of a test result with a value of $\mathrm{P}<0.100$, the population was considered not normally distributed, and consequently the comparison was performed using statistical tests independent of variance, i.e. determination of the Mann-Whitney U or Wilcoxon's signed rank test, where appropriate.

The categorical variables have been described as percentages and compared with a chi-square test with Yates correction due to the limited number of subjects. A value of $\mathrm{P}=0.05$ was considered statistically significant.

\section{Results}

Results. Of the 132 obese patients selected, 77 (58.3\%) underwent laparoscopy and $55(41.3 \%)$ laparotomy. The mean age of patients at the time of diagnosis was 65.4 years.

The patients' demographic characteristics are shown in Table I. The average body mass index (BMI) was $35.9 \mathrm{~kg} / \mathrm{m}^{2}$ (range $30.08-60.97 \mathrm{~kg} / \mathrm{m}^{2}$ ). Class I, II, III and IV of obesity were present in 53.2 vs. $52.7 \%, 24.7$ vs. $27.3 \%$, 14.3 vs. $14.5 \%$, and 7.8 vs. $5.5 \%$ for the laparoscopic vs. open abdominal groups, respectively.
The most frequent comorbidity reported was hypertension $(70.56 \%)$, followed by diabetes $(44.33 \%)$, cardiovascular disease $(22.7 \%)$, metabolic syndrome (20.5\%) and hypothyroidism $(20.5 \%)$. The latter condition was significantly more frequent in the open abdominal than in the laparoscopic group $(\mathrm{P}=0.006)$. In $68.2 \%$ of the cases, endometrial cancer occurred at stage IA disease and in $65.2 \%$ the neoplasms were graded G1. Of the 90 patients diagnosed at stage IA, $62(68.9 \%)$ underwent laparoscopic surgery and $28(31.1 \%)$ open abdominal surgery with a statistically significant difference in the distribution within the two groups $(\mathrm{P}=0.002)$. Stage and grading in the two groups are shown in Table II.

Pre-operative phase. Chest $\mathrm{X}$-ray $(\mathrm{P}<0.001)$, lower limb eco-Doppler $(\mathrm{P}=0.047)$ and chemical urinalysis $(\mathrm{P}<0.001)$ were required more often in the open surgery group. In terms of costs, the median expenditure per patient was $€ 1.93$ vs. $€ 12.85$ for X-ray, $€ 9.12$ vs. $€ 15.96$ for eco-Doppler and $€ 0.74$ vs. $€ 2.4$ for chemical examination of urine in the laparoscopic and open abdominal groups respectively.

The median total cost of pre-operative examinations for each single patient was $€ 11.79$ and $€ 31.21$ in the laparoscopic and open abdominal groups, respectively, with a difference of $€ 19.42$ in favor of the laparoscopic group. 
Table II. Tumors staging and grading.

\begin{tabular}{lrrrr}
\hline & All patients & $\frac{\text { Laparoscopy }}{n=77(58.3 \%)}$ & $\frac{\text { Laparotomy }}{n=55(41.7 \%)}$ & P-value \\
\cline { 2 - 3 } Variable & $n=132$ & & & 0.002 \\
Staging & $90(68.2 \%)$ & $12(15.6 \%)$ & $17(30.9 \%)$ & \\
IA & $29(22.0 \%)$ & $02(\%)$ & $4(7.3 \%)$ & \\
IB & $4(3.0 \%)$ & $2(2.6 \%)$ & $5(1.8 \%)$ & 0.081 \\
II & $3(2.3 \%)$ & $1(1.3 \%)$ & $30(54.5 \%)$ & \\
III & $6(4.5 \%)$ & $56(72.7 \%)$ & $17(30.9 \%)$ & \\
IV & & $16(20.8 \%)$ & $8(14.5 \%)$ & \\
Grading & $86(65.2 \%)$ & $5(6.5 \%)$ & & \\
G1 & $33(25.0 \%)$ & $13(9.8 \%)$ & & \\
G2 & & & \\
G3 & &
\end{tabular}

Intra-operative phase. Intraoperative details are shown in Table III. Operative time was shorter in the laparoscopic group. A statistical analysis of the average hourly cost of the operating room was not performed because the University Hospital of Parma is a public facility and it doesn't influence the overall cost of the operation.

At the University Hospital of Parma, the instrumentation and the surgical materials used during the laparoscopic procedures performed costed $€ 511.27$ compared to $€ 420.36$ for laparotomy.

Of the 56 patients undergoing lymphadenectomy, 20 patients were submitted to laparoscopy and 36 (with lumboaortic lymphadenectomies) to laparotomy $(\mathrm{P}<0.001)$. Cost of lymphadenectomy has been included as part of the overall costs of the surgical procedure itself.

The need for peritoneal drainage was lower in the laparoscopic group (64.9 vs. $100 \%)$, with a median cost per capita of $€ 7.63$ vs. $€ 11.75$.

Overall, $5.2 \%$ of patients operated by laparoscopy required placement of a central venous catheter, compared to $25.5 \%$ of patients who underwent laparotomy $(\mathrm{P}=0.001)$, with a median cost of $€ 3.11$ vs. $€ 15.24$, respectively.

Total intraoperative cost for laparoscopy and laparotomy was $€ 755.09$ and $€ 969.13$, respectively, with an excess of $€ 214.04$ in the laparotomy group.

No difference was found in terms of intraoperative complications (vascular, bladder or intestinal lesions) between the two groups (13 vs. $18.2 \%$ in the laparoscopic and open abdominal group, respectively; $\mathrm{P}=0.566$ ).

Post-operative phase. Details of the postoperative course are provided in Table IV. The average length of stay was longer for patients operated by laparotomy: 9.4 days compared to 5.1 days for patients operated by laparoscopy $(\mathrm{P}=0.683)$. This implied an almost double median hospitalization cost in the open abdominal group compared to the laparoscopic group (€4805.37 vs. €2589.25; $\mathrm{P}<0.0001$ ).

Eighteen patients required intensive care hospitalization. The median cost per capita was $€ 233.08$ for laparoscopy and $€ 512.78$ for laparotomy $(\mathrm{P}=0.090)$.
Of the 9 total patients who required a transfusion of concentrated red cells, 8 were part of the open abdominal group. The average expenditure per patient in terms of blood bags transfused was $€ 39.49$ for the open abdominal arm compared to $€ 3.53$ in the laparoscopic group $(\mathrm{P}=0.003)$. The hemoglobin drop was $0.5 \mathrm{~g} / \mathrm{dl}$ in the open abdominal group vs. $0.3 \mathrm{~g} / \mathrm{dl}$ in the laparoscopic group. Also the number of blood tests $(\mathrm{P}<0.001)$, blood count $(\mathrm{P}<0.001)$, hemogasanalysis $(\mathrm{P}=0.001)$, tests of hemostatic control function $(\mathrm{P}<0.001)$ were higher in the open abdominal group. Table IV shows that postoperative electrocardiogram $(\mathrm{P}<0.001), \mathrm{CT}$ scan $(\mathrm{P}=0.034)$, and chest $\mathrm{X}$-ray $(\mathrm{P}<0.001)$ were more frequent in the open abdominal arm with a consequent increase of the costs per capita.

Evaluation by another specialist (cardiologist, diabetologist, internist) was necessary in $30.9 \%$ of laparotomies vs. $10.4 \%$ of laparoscopies $(\mathrm{P}=0.003)$, with an expense of $€ 18.71$ vs. $€ 11.45$ respectively.

A respiratory support was applied to 38 patients (28.8\%), of whom $23(41.8 \%)$ were in the open abdominal arm $(\mathrm{P}=0.011)$. Oxygen therapy entailed a medical health expenditure of $€ 4.05$ in the open abdominal group vs. $€ 2.97$ of minimally invasive surgery. No difference in costs was shown in the antithrombotic prophylaxis in the two arms, with a median cost of $€ 37.88$.

No significant difference was found also in terms of post-operative antibiotic therapy. Considering pain control, after laparotomy the most used drugs were Morphine (36.4\%), Ropivacain (20\%) and Ketoprofen (45.5\%). Following laparoscopic surgery, the most frequently used drugs were Paracetamol (80.5\%) and Ketorolac (41.6\%). Antibiotic and pain-relief therapies resulted in a significantly higher cost for the open abdominal than for the minimally-invasive approach, with a cost for each patient of $€ 5.40$ vs. $€ 3.71$, respectively $(\mathrm{P}=0.027)$.

The cost of a single gynecological examination is $€ 18.00$. Thirty-two total gynecological checks were performed outside the standard follow-up visits. Twenty-three patients operated by laparotomy required extra gynecological post-operative controls, vs. 9 patients in the laparoscopic group. The average cost for post-operative gynecological check-ups was $€ 7.53$ and $€ 2.10$ for the open and laparoscopic groups, respectively. 
Table III. Intraoperative phase.

\begin{tabular}{|c|c|c|c|c|}
\hline & All patients & Laparoscopy & Laparotomy & \\
\hline Characteristics & $n=132$ & $n=77(58.3 \%)$ & $n=55(41.7 \%)$ & P-value \\
\hline Operative time (min) & 156.8 & 117.0 & 212.5 & $<0.001$ \\
\hline Intraoperative complications & $20(15.2 \%)$ & $10(13.0 \%)$ & $10(18.2 \%)$ & 0.566 \\
\hline Use of drainage & $105(79.5 \%)$ & $50(64.9 \%)$ & $55(100 \%)$ & $<0.001$ \\
\hline Placement of central venous catheters & $18(13.6 \%)$ & $4(5.2 \%)$ & $14(25.5 \%)$ & 0.001 \\
\hline Use of intraoperative drugs & $11(8.3 \%)$ & $7(9.0 \%)$ & $4(7.2 \%)$ & 0.413 \\
\hline
\end{tabular}

Table IV. Post-operative phase.

\begin{tabular}{|c|c|c|c|c|}
\hline & All patients & Laparoscopy & Laparotomy & \\
\hline Variable & $n=132$ & $n=77(58.3 \%)$ & $n=55(41.7 \%)$ & P-value \\
\hline Hospital stay (days) & 6.9 & 5.1 & 9.4 & 0.683 \\
\hline Critical care unit (any access) & $18(13.6 \%)$ & $7(9.1 \%)$ & $11(20.0 \%)$ & 0.072 \\
\hline Total blood count (number) & 2.9 & 2.1 & 3.8 & $<0.001$ \\
\hline Blood trasfusion & $9(6.8 \%)$ & $1(1.3 \%)$ & $8(14.5 \%)$ & 0.003 \\
\hline Thromboembolism therapy & $131(99.2 \%)$ & $77(100 \%)$ & $54(98.2 \%)$ & 0.232 \\
\hline Early complications (<30 days) & $50(37.9 \%)$ & $18(23.4 \%)$ & $32(58.2 \%)$ & $<0.001$ \\
\hline Late complications (>30 days) & $18(13.6 \%)$ & $7(9.1 \%)$ & $11(20.0 \%)$ & 0.072 \\
\hline Medical consultations & $25(18.9 \%)$ & $8(10.4 \%)$ & $17(30.9 \%)$ & 0.003 \\
\hline Respiratory support (any) & $38,28.8 \%$ & $15,19.5 \%$ & $23(41.8 \%)$ & 0.011 \\
\hline Antibiotic therapy & $12(9.1 \%)$ & $6(7.8 \%)$ & $6(10.9 \%)$ & 0.539 \\
\hline \multicolumn{5}{|l|}{ Pain reliever therapies } \\
\hline Naropine & $12(9.1 \%)$ & $1(1.3 \%)$ & $11(20.0 \%)$ & $<0.001$ \\
\hline Ketoprophene & $45(34.1 \%)$ & $20(26.0 \%)$ & $25(45.5 \%)$ & 0.020 \\
\hline Morphine & $28(21.2 \%)$ & $8(10.4 \%)$ & $20(36.4 \%)$ & $<0.001$ \\
\hline Toradol & $43(32.6 \%)$ & $32(41.6 \%)$ & $11(20.0 \%)$ & 0.009 \\
\hline Perfalgan & $91(68.9 \%)$ & $62(80.5 \%)$ & $29(52.7 \%)$ & 0.001 \\
\hline CT scan & $7(5.3 \%)$ & $1(103 \%)$ & $6(10.9 \%)$ & 0.015 \\
\hline EEG & $34(25.8 \%)$ & $27(49.1 \%)$ & $7(9.1 \%)$ & $<0.001$ \\
\hline Chest X-ray & $20(15.2 \%)$ & $4(5.2 \%)$ & $16(29.1 \%)$ & $<0.001$ \\
\hline
\end{tabular}

CT, computed tomography scan; ECG, electrocardiography.

Comparing the two surgical techniques, minimally invasive surgery appeared to be more advantageous in terms of post-operative overall costs, with an average cost of $€ 3646.53$ vs. $€ 6322.83$ in the open technique $(\mathrm{P}<0.0001)$. Therefore, median post-operative costs for single patient was $€ 2676.30$ higher in the laparotomy group.

Both early $(\mathrm{P}<0.01)$ and late $(\mathrm{P}=0.072)$ complications were more frequently observed in the open abdominal group, as shown in Table V. Among the early complications only the dehiscence of the surgical wound reached statistical significance $(12.7 \%$ vs. no cases in the open and laparoscopic groups, respectively). The most frequent major postoperative complication was represented by incisional hernia [14.5\% of patients who underwent laparotomy compared to $5.2 \%$ of patients who had laparoscopy $(\mathrm{P}=0.065)]$.
Considering all the pre-, intra- and post-operative course, the expenses for an obese patient operated by laparoscopy was $€ 4412.41$ vs. $€ 7323.17$ by open surgery, with an average saving of $€ 2911.03$ in favor of minimally-invasive surgery (see Table VI).

\section{Discussion}

As expected, in our series we observed a median excess expenditure of $€ 2911.03$ per capita for obese patients operated by laparotomy compared to laparoscopy. Therefore, the present study shows that minimally invasive surgery is more advantageous both in terms of costs and of patients' outcomes, compared to traditional open surgery.

The results obtained in our study are in line with others that have reported an economic advantage when using a 
Table V. Complications.

\begin{tabular}{|c|c|c|c|c|}
\hline & All patients & Laparoscopy & Laparotomy & \\
\hline Early complications (any) & $n=132(\%)$ & $n=77(58.3 \%)$ & $n=55(41.7 \%)$ & P-value \\
\hline Respiratory distress & $15(11.4)$ & $6(7.8 \%)$ & $9(16.4 \%)$ & 0.578 \\
\hline Hypertensive crisis & $10(7.6)$ & $5(6.5 \%)$ & $5(9.1 \%)$ & 0.578 \\
\hline Anemia & $9(6.8)$ & $4(5.2 \%)$ & $5(9.1 \%)$ & 0.397 \\
\hline Systemic infections & $4(3.0)$ & $2(2.6 \%)$ & $2(3.6 \%)$ & 0.810 \\
\hline Deep vein thrombosis & $2(1.5)$ & $0(\%)$ & $2(3.6 \%)$ & 0.092 \\
\hline Surgical site infections & $3(2.3)$ & $1(1.3 \%)$ & $2(3.6 \%)$ & 0.374 \\
\hline Surgical site dehiscence & $7(5.3)$ & $0(\%)$ & $7(12.7 \%)$ & 0.001 \\
\hline Late complications (any) & $18(13.6)$ & $7(9.1 \%)$ & $11(20.0 \%)$ & 0.072 \\
\hline Laparocele/incisional hernia & $12(9.1)$ & $4(5.2 \%)$ & $8(14.5 \%)$ & 0.065 \\
\hline
\end{tabular}

Early complications, within 30 days from surgery; Late complications, over 30 days from surgery.

Table VI. Total costs (means).

\begin{tabular}{|c|c|c|c|c|}
\hline & All patients & Laparoscopy & Laparotomy & \\
\hline Variables & $n=132$ & $n=77(58.3 \%)$ & $n=55(41.7 \%)$ & P-value \\
\hline Hospital stay & 3512.63 & 2589.25 & 4805.37 & $<0.0001$ \\
\hline Operation costs & 477.26 & 511.27 & 420.36 & $<0.0001$ \\
\hline Critical care unit & 349.62 & 233.08 & 512.78 & 0.090 \\
\hline Medical consultations & 14.47 & 11.45 & 18.71 & 0.062 \\
\hline Blood exams & 214.24 & 17.55 & 269.82 & $<0.0001$ \\
\hline Deep vein thrombosis prophylaxis & 37.88 & 38.96 & 36.36 & 0.171 \\
\hline $\mathrm{O} 2$ therapy & 3.42 & 2.97 & 4.05 & 0.593 \\
\hline Drugs therapy & 4.41 & 3.71 & 5.40 & 0.027 \\
\hline Blood transfusion & 18.41 & 3.53 & 39.49 & 0.010 \\
\hline Drainage & 9.35 & 7.63 & 11.75 & $<0.0001$ \\
\hline Central venous access & 8.16 & 3.11 & 15.24 & 0.002 \\
\hline X-ray & 9.58 & 2.90 & 18.94 & $<0.0001$ \\
\hline MRI & 37.80 & 32.40 & 45.35 & 0.416 \\
\hline $\mathrm{CT}$ & 9.28 & 2.27 & 19.10 & 0.034 \\
\hline ECG & 4.36 & 1.30 & 8.63 & $<0.0001$ \\
\hline Echocardiography & 7.82 & 7.38 & 8.45 & 0.745 \\
\hline Doppler lower limbs & 11.97 & 9,12 & 15.96 & 0.055 \\
\hline
\end{tabular}

MRI, magnetic resonance imaging; CT, computed tomography scan; ECG, electrocardiography.

laparoscopic technique $(18,19,27,29)$. While most of the previous studies have analyzed the difference between the costs of obese patients compared to non-obese patients or laparoscopy compared to laparotomy in the overall populations, our study compares the two surgical approaches analyzing only the subset of obese patients. Even more importantly, our study has the merit of a detailed and comprehensive evaluation of all the direct and indirect costs connected to the different surgical procedures.

An important aspect of our analysis is that the demographic distribution of our patients is homogeneous in the two groups in terms of comorbidity, age, BMI classes, menopausal status and ASA score.

The cost analysis was divided into the pre-, intra- and post-operative phases to better understand in which setting there is a greater expense in one vs. the other technique. These data may allow a better understanding regarding the possibility of improving the management of these specific patients.

As expected, expenditure in the preoperative phase is almost superimposable in the two groups, given the similar demographic characteristics of the patients included. In the intra- and post-operative phase, the major economic differences were 
mainly due to the increased of laparotomy and to the higher incidence of postoperative complications and admission to intensive care unit in the open abdominal technique.

As a secondary aim of the present study we observed, in line with the LAP2 study, that laparoscopy turns out to be a safe surgical technique in terms of intraoperative and postoperative complications (12). Pelvic lymphadenectomy was performed in 56 total patients, 20 were patients in the laparoscopic group and 34 in the open group. Only 2 patients underwent aortic lymphadenectomy and were included in the traditional abdominal surgery. This may reflect the fact that $80.5 \%$ of the patients in the laparoscopic group had stage IA disease vs. $50.9 \%$ in the open abdominal group. Of course, this finding may be associated with an inherent selection bias of our retrospective study, i.e. the tendency to operate by open surgery patients at a more advanced stage.

Regarding the other possible limitations of our study, we mention its retrospective nature, the very long study period (with a wide variation in terms of implementation of laparoscopic techniques) and the fact that the choice regarding the surgical approach, was made at surgeons' discretion. Nonetheless, in a secondary analysis based on the intention-to-treat principle, we observed that still laparoscopy was associated with a saving of $>€ 2500$ per patient.

On the other hand, our study has also several merits: It should be stressed that we selected only obese patients, thus providing more focused and useful data, in a population of patients which is rapidly increasing. Patients with a similar incidence of comorbidities were included in the two groups. Surgical techniques have been standardized and only two surgeons (with extensive background in gynecologic oncologic surgery) were involved. Finally, our cost-analysis has been extremely thorough and detailed, and allowed us to provide reliable and realistic data.

In conclusion, this study demonstrates that minimally invasive techniques are preferable to open surgery both in terms of cost per patient and in terms of peri-operative complications in the setting of obese patients. For every woman operated by laparoscopy at the university of Parma more almost 3000 EUR have been saved compared to laparotomy. These findings should be taken into account in an era in which technological innovations have to be balanced against a strong attention to health care costs.

\section{Acknowledgements}

Not applicable.

\section{Funding}

No funding was recevied.

\section{Availability of data and materials}

All data generated or analyzed during this study are included in this published article.

\section{Authors' contributions}

VAC, GS, RB, VC and SU were involved in conceptualization of the study. GG, AC, LM, MG were invovled in the data acquisition, analysis and interpretation. MR was invovled in the interpretation of data and statistical analysis. All authors read and approved the manuscript and agree to be accountable for all aspects of the research in ensuring that the accuracy or integrity of any part of the work are appropriately investigated and resolved.

\section{Ethics approval and consent to participate}

Project 266/2018/OSS/AOUPR was considered exempt on May 18, 2018 by the Partners HealthCare IRB.

\section{Patient consent for publication}

All participants gave their consent to the use of personal data for scinetific purposes.

\section{Competing interests}

The authors declare that they have no competing interests.

\section{References}

1. NCD Risk Factor Collaboration (NCD-RisC): Worldwide trends in body-mass index, underweight, overweight, and obesity from 1975 to 2016: A pooled analysis of 2416 population-based measurement studies in 128.9 million children, adolescents and adults. Lancet 390: 2627-2642, 2017.

2. Wold Health Organization: WHO Regional Office for Europe and the Directorate-General for Health and Consumers of the European Commission. Methodology and summary. World Health Organization, Copenhagen, 2013.

3. Osservasalute Report: State of health and quality of assistance in the Italian regions, 2016. https://www.osservatoriosullasalute.it/ wp-content/uploads/2017/05/ro-2016.pdf. Accessed September 5, 2018.

4. Arterburn DE, Maciejewski ML and Tsevat J: Impact of morbid obesity on medical expenditures in adults. Int J Obes (Lond) 29: 334-339, 2005.

5. Uccella S, Bonzini M, Palomba S, Fanfani F, Ceccaroni M, Seracchioli R, Vizza E, Ferrero A, Roviglione G, Casadio P, et al: Impact of obesity on surgical treatment for endometrial cancer: A multicenter study comparing laparoscopy vs. open surgery, with propensity-matched analysis. J Minim Invasive Gynecol 23: 53-61, 2016.

6. Obermair A, Brennan DJ, Baxter E, Armes JE, Gebski V and Janda M: Surgical safety and personal costs in morbidly obese, multimorbid patients diagnosed with early-stage endometrial cancer having a hysterectomy. Gynecol Oncol Res Pract 3: 1, 2016.

7. Sankaranarayanan R and Ferlay J: Worldwide burden of gynaecological cancer: The size of the problem. Best Pract Res Clin Obstet Gynaecol 20: 207-225, 2006.

8. Siegel R, Ma J and Jemal A: Cancer statistics, 2014. CA Cancer J Clin 64: 9-29, 2014.

9. Ghezzi F, Cromi A, Uccella S, Siesto G, Zefiro F and Bolis P: Incorporating laparoscopy in the practice of a gynecologic oncology service: Actual impact beyond clinical trials data. Ann Surg Oncol 16: 2305-2314. 2009.

10. Gueli Alletti S, Rossitto C, Cianci S, Restaino S, Costantini B, Fanfani F, Fagotti A, Cosentino F and Scambia G: Telelap ALF-X vs. standard laparoscopy for the treatment of early-stage endometrial cancer: A single-institution retrospective cohort study. J Minim Invasive Gynecol 23: 378-383, 2016.

11. Rossitto C, Gueli Alletti S, Rotolo S, Cianci S, Panico G and Scambia G: Total laparoscopic hysterectomy using a percutaneous surgical system: A pilot study towards scarless surgery. Eur J Obstet Gynecol Gynecol Reprod Biol 203: 132-135, 2016.

12. Walker JL, Piedmonte MR, Spirtos NM, Eisenkop SM, Schlaerth JB, Mannel RS, Spiegel G, Barakat R, Pearl ML and Sharma SK: Laparoscopy compared with laparotomy for comprehensive surgical staging of uterine cancer: Gynecologic oncology group study LAP2. J Clin Oncol 27: 5331-5336, 2009. 
13. Gehrig PA, Cantrell LA, Shafer A, Abaid LN, Mendivil A and Boggess JF: What is the optimal minimally invasive surgical procedure for endometrial cancer staging in the obese and morbidly obese woman. Gynecol Oncol 111: 41-45. 2008.

14. Uccella S, Cromi A, Bogani G, Casarin J, Formenti G and Ghezzi F: Systematic implementation of laparoscopic hysterectomy independent of uterus size: Clinical effect. J Minim Invasive Gynecol 20: 505-516, 2013.

15. Onstad MA, Schmandt RE and Lu KH: Addressing the role of obesity in endometrial cancer risk prevention and treatment. J Clin Oncol 34: 4225-4230, 2016.

16. Eltabbakh GH, Shamonki MI, Moody JM and Garafano LL: Hysterectomy for obese women with endometrial cancer: Laparoscopy or laparotomy. Gynecol Oncol 78: 329-335, 2000.

17. Scribner DR Jr, Walker JL, Johnson GA, McMeekin DS, Gold MA and Mannel RS: Laparoscopic pelvic and paraaortic lymph node dissection in the obese. Gynecol Oncol 84: 426-430, 2002.

18. Elsahwi KS, Hooper C, De Leon MC, Gallo TN, Ratner E, Silasi DA, Santin AD, Schwartz PE, Rutherford TJ and Azodi M Comparison between 155 cases of robotic vs. 150 cases of open surgical staging for endometrial cancer. Gynecol Oncolc 124: 260-264, 2012

19. Lu Z, Yi X, Feng W, Ding J, Xu H,Zhou X and Hua K: Cost-benefit analysis of laparoscopic surgery versus laparotomy for patients with endometrioid endometrial cancer: Experience from an institute in China. J Obstet Gynaecol Res 38: 1011-1017, 2012.

20. Spirtos NM, Schlaerth JB, Gross GM, Spirtos TW, Schlaerth AC and Ballon SC: Cost and quality-of-life analyses of surgery for early endometrial cancer: Laparotomy versus laparoscopy. Am J Obstet Gynecol 174: 1795-1800, 1996.

21. Bell MC, Torgerson J, Seshadri-kreaden U, Wierda A and Hunt S: Comparison of outcomes and cost for endometrial cancer staging via traditional laparotomy standard laparoscopy and robotic techniques. Gynecol Oncol 111: 407-411, 2008

22. Bijen CB, Vermeulen KM, Mourits MJ, Arts HJ, Ter Brugge HG, van der Sijde R, Wijma J, Bongers MY, van der Zee AG and de Bock GH: Cost effectiveness of laparoscopy versus laparotomy in early stage endometrial cancer: A randomised trial. Gynecol Oncol 121: 76-82, 2011.
23. World Health Organization. Obesity: Preventing and managing the global epidemic. Report of a WHO Consultation on Obesity, Geneva, June 3-5, 1997. https://apps.who.int/iris/ handle/10665/63854. Accessed September 5, 2018.

24. National Heart, Lung, and Blood Institute: Obesity Education Initiative Expert Panel on the identification, Evaluation, and Treatment of Obesity in Adults at High Risk for Cardiovascular Disease. Clinical Guidelines on the Identification, Evaluation, and Treatment of Overweight and Obesity in Adults. National Heart Lung and Blood Institute (ed.). National Institutes of Health, Bethesda MD, 1998.

25. Colombo N, Creutzberg C, Amant F, Bosse T, González-Martín A, Ledermann J, Marth C, Nout R, Querleu D, Mirza MR, et al: ESMO-ESGO-ESTRO Consensus conference on endometrial cancer: Diagnosis treatment and Follow-up. Int J Gynecol Cancer 27: 16-41. 2016.

26. Querleu D and Morrow CP: Classification of radical hysterectomy. Lancet Oncol 9: 297-303, 2008.

27. Uccella S, Bonzini M, Malzoni M, Fanfani F, Palomba S, Aletti G, Corrado G, Ceccaroni M, Seracchioli R, Shakir F, et al: The effect of a uterine manipulator on the recurrence and mortality of endometrial cancer: A multi-centric study by the Italian society of gynecological endoscopy. Am J Obstet Gynecol 216: 592. e1-592.e11, 2017.

28. Chassagne D, Sismondi P, Horiot JC, Sinistrero G, Bey P, Zola P, Pernot M, Gerbaulet A, Kunkler I and Michel G: A glossary for reporting complications of treatment in gynecological cancers. Radiother Oncol 26: 195-202, 1993.

29. Suidan RS, He W, Sun CC, Zhao H, Fleming ND, Ramirez PT, Soliman PT, Westin SN, Lu KH, Giordano SH and Meyer LA: Impact of body mass index and operative approach on surgical morbidity and costs in women with endometrial carcinoma and hyperplasia. Gynecol Oncol 145: 55-60, 2017.

This work is licensed under a Creative Commons Attribution-NonCommercial-NoDerivatives 4.0 International (CC BY-NC-ND 4.0) License. 